\title{
LOS ORÍGENES DEL MONÓLOGO DRAMÁTICO: EL DIT DE L'HERBERIE DE RUTEBEUF
}

Alicia Yllera

$U N E D$

Existen, en Francia, desde el siglo xIII, siendo el primero conservado el Dit de l'Herberie de Rutebeuf, una serie de obras de carácter cómico-burlesco que encerraban en ciernes los orígenes de la farsa de un personaje de los siglos XVI y XVII, cuyo valor dramático es evidente, desde un punto de vista histórico, pero parece haber sido escasamente apercibido por los contemporáneos, habituados a una presentación oral de géneros muy diversos, para quienes era simplemente un género cómico, que sólo difería por el tema del fabliau o del dit plaisant et descriptif.

En la segunda mitad del siglo XV se multiplicaron los monólogos en los que un personaje alaba sus propias habilidades (monólogos de herbiers, mires, valets, etc.), su valentía (soldados fanfarrones y brabucones), o celebra irónica o ridículamente su "estado sentimental» (enamorados). Destacan esencialmente los del segundo grupo. Algunos presentan un tema ya cultivado en la Antigüedad: la desmitificación de la valentía militar. El tema del miles gloriosus de Plauto, unido al del Babio medieval, producirá el personaje del Franc Archer de Bagnolet (París, hacia 1468)', expresión del descontento y del desprecio popular hacia los «Francs Archers", creados por Carlos VII en 1448, suprimidos por Luis XI en 1480 y restablecidos por Francisco I en 1521. Otros hacen intervenir a un personaje típicamente medieval: el herboriste, antepasado del curandero, que constituye con el mire (médico) el grupo de los charlatanes, embaucadores de enfermos, cuyos

1 Ed. Picot y Nyrop, 1880. La obra tuvo gran éxito: fue imitada en el Franc Archier de Cherré (par Jehan Daniel, dit maistre Mithou), representada en los carnavales de Angers en 1524. 
ecos, juntó a los de los criados astutos y entrometidos, Ilegarán a la comedia «clásica» con Molière.

Los más antiguos monólogos conservados hacen intervenir a un herboriste o mire, siendo Rutebeuf, en el estado actual de nuestros conocimientos, el iniciador del género.

La parodia del discurso del charlatán dio lugar a diversas obras medievales: nos han llegado dos Herberies ${ }^{2}$, una perorata de mire, La Goute en l'aine, y un Dit du Mercier en el siglo XIII. Tras un largo eclipse de este personaje en el monólogo, en el siglo XVI aparece la Fille batelière, fiel sirvienta de un bateleur, experta en drogas y remedios extraordinarios.

El carácter dramático del Dit de l'Herberie de Rutebeuf fue discutido por Petit de Julleville, basándose en la carencia de acción y juego escénico, en su forma lírica y en la mezcla de una parte en verso y otra en prosa ${ }^{3}$. El carácter dramático de la obra reside, para nosotros, más en una consideración histórica que en el modo de presentación al público de la época que no difería, esencialmente, del de toda la literatura "recitada" y "recreada» por juglares. Su acción y juego escénico, por otra parte, no son inferiores a los de la mayoría de los monólogos de los siglos XV y XVI. El teatro francés medieval utilizó el verso, sin duda, pero en el monólogo cómico muy pronto se introdujo la prosa, como nos muestran la Charte de la Paix aux Anglais, la Nouvelle Charte de la Paix aux Anglais y l'Herberie anónima, todos ellos del siglo XIII.

El metro elegido, para la parte versificada, no puede considerarse lírico: Rutebeuf escribió en él diez poemas, incluyendo los párrafos del Miracle de Théophile: Du Pharisien; Complainte de Guillaume de Saint-Amour, Griesche d'hiver, Griesche d'été, Renart le Bestourné, Mariage Rutebeuf, Complainte Rutebeuf, Ave Maria Rutebeuf, Herberie. El tipo métrico no aparece rígidamente adscrito a un género pero, salvo en el Ave Maria Rutebeuf y en el Miracle de Théophile, aparece esencialmente en composiciones burlescas y satíricas. Idéntica distribución figura en las obras que lo utilizarán posteriormente: Privilège aux Bretons, Rêveries, Cornetes, Dan Denier, Un Dit de Vérité, Ditié des choses qui faillent en ménage, Lande dorée, Un Salut d'Amour.

${ }^{2}$ La de Rutebeuf y una Herberie totalmente en prosa.

3. Señaló que «Cité souvent comme dramatique, mais à tort. ll n'offre aucune action, nul jeu de scène; la forme est plutôt lyrique; la pièce est en tercets, composés de deux vers de huit syllabes, suivis d'un vers de quatre. Un long épisode en prose (langue ignorée du théâtre jusqu'à la Renaissance) succède aux couplets lyriques»" (Petit de Julleville, 1886b: 407; cf. también, $1885 ; 24-26)$. El argumento de la prosa fue rebatido por Picot $(1970 ; 123)$ : «c'est lá, ce nous semble une erreur. Sans doute dans un mystère ou même dans une farce, notre ancien théâtre n'admettrait que les vers; mais il n'en était pas de même dans les monologues). Cita el ejemplo de dos sermons joyeux que emplean la prosa: Sermon de Frappe culz; Sermon joyeux de monsieur saint Velu; ambos son del siglo xvi, «mais, les auteurs d'alors conservaient fidelement des traditions anciennes, traditions qui ne furent rompues que par les poètes de la Pléiade». 
En este metro se compusieron diversos mimos (Privilège aux Bretons, etc.), debido a su comodidad de retención: el tetrasílabo completa la frase precedente e introduce, por la rima, el terceto siguiente. Su empleo para sus llamadas "poesías personales» no bastaría para confirmar su carácter lírico, bastante contestable, por otra parte, en estas composiciones. La habilidad esencial de Rutebeuf consiste, en estas obras, en acercar la parodia al original, a la realidad, y hacerla pasar por tal. Las desgracias del hombre casado, los lamentos contra el matrimonio y, por supuesto, contra las mujeres son uno de los entretenimientos favoritos de clérigos y escolares, uno de los temas más tratados de toda la Edad Media. Rutebeuf no es un innovador en el tema; lo es por imprimirle un sesgo personal que ha hecho que el lector moderno lo interprete como obra autobiográfica. Recuerdos librescos y experiencias vividas se funden en su obra, siempre a mitad de camino entre la burla, la parodia y la compasión, que hace de él uno de los más interesantes representantes de la ironía medieval. Como la mayoría de los juglares de su época, se rie de las diversas situaciones penosas, pero su risa tiene un carácter de profundidad que falta a los demás: a su risa se añade un sentimiento de compasión pesimista. El mundo es una fuente inagotable de recursos cómicos pero, a la vez, es un mundo que se desintegra, en el que los hombres son ridículos en sus actuaciones pero también son desgraciados. Mezcla de burla y compasión, de convencionalismos y originalidad, recuerdos librescos y recuerdos vividos, dualidades de Rutebeuf que explican interpretaciones contrapuestas: como primer representante de la poesía lírica personal en la Edad Media o como goliardo que adapta al francés una tradición esencialmente latina.

$L$ 'Herberie anónima en prosa ${ }^{4}$ no difiere considerablemente de la obra de Rutebeuf: la última es más recogida, la primera, verdadera exhibición de charlatán, acentúa el carácter grosero de la obra, actúa por meandros, digresiones, desviaciones y explicaciones apenas relacionadas con el elogio de la hierba - paréntesis de charlatán que, fingiendo haber abandonado su propósito, vuelve, al final, a insistir sobre él con un nuevo argumento-. Incluye un rápido diálogo basado en el equívoco:

- Ou fustes vos nez?

- Ge ne fui onques ne nef ne bateax.

-De quel vile este vos?

-De la vile enprés l'aitre.

-Ou siet li aitres?

4. Editada por Faral y Bastin, Rutebeuf, Oeuvres complètes II, pp. 268-271. Se citará por esta edición (que se abreviará en FB). 
-Entor lc mostier.

-Ou siet li mostiers?

-Sor terre.

(FB, II: 271)

Pero la burla está más exagerada: es difícil confundir el original con la caricatura. La habilidad de Rutebeuf consiste en empañar las diferencias entre ambos; él escribe caricaturas, parodias, en muchos casos interpretadas como obras serias: en sus momentos de mayor miseria, ¿por qué no?, Rutebeuf habría hecho la competencia a los charlatanes ambulantes; acurrucado en un rincón del mercado, habría extendido su mercancía. Así lo interpretó Petit de Julleville ${ }^{5}$ e incluso su primer editor, Jubinal ${ }^{6}$, interpretación refutada por Faral'. Incluso modernamente, se ha pensado que la segunda parte en prosa podría ser la transcripción fiel del discurso de un «herborista»".

Un personaje, encaramado en una banqueta, imita al charlatán herborista. Su primera tarea será atraerse al público y lograr su silencio. Tras esto se presenta: El Cairo, la Morería, Salerno, Apulia, Calabria... han sido el escenario de su aprendizaje. Nombres de ciudades reales e imaginarias se

${ }^{5}$ «Rutebeuf l'a-t-il composé [ce morceau très curieux] pour son propre usage, et fit-il, dans ses jours de misère, quand les dés l'avaient maltraité, le métier d'opérateur sur la place publique? Ou bien a-t-il composé le dit de l'Erberie pour le vendre à quelque charlatan qui en régalait les badauds? Ou enfin, le dit n'est-il qu'une imitation artistique des «boniments» réels que débitaient les marchands de drogues, et servait-il à des jongleurs qui parodiaient les opérateurs sans faire eux-mêmes métier d'opérateurs? Cette hypothèse est admissible; mais on ne saurait prouver qu'elle est vraie; car, pour que l'imitation fút bien faite, il fallait, dans ce dernier cas, qu'elle ressemblât parfaitement à la réalité: rien ne peut donc permettre aujourd'hui de distinguer l'une de l'autre") (1885: 25).

${ }^{6}$ "C'est tout simplement une parade, un boniment, dans le genre de ceux que les charlatans d'aujourd'hui débitent sur les places publiques. Seulement Rutebeuf l'y récitait-il lui-même, ou l'avait-il composé comme un modèle à l'usage des jongleurs et des trouvères de bas étage? Je l'ignore mais il me répugne de croire que l'auteur des plaintes éloquentes sur la Terre-Sainte, qu'on lira plus loin, ait pu s'abaisser à hurler de pareilles sornettes et des plaisanteries aussi grossières dans un carrefour." (RUTEBEUF, Oeuvres, II: 51, n. 1; Cf. Lintilhac, 1973 Il: 160).

'Faral (1910: 55-59) da las pruebas, externas e internas, que justifican su hipótesis de que es una «imitación burlesca»: «l'accumulation voulue de bourdes et de "rêveries", dont ils sont tout enflés» y el testimonio del fabliau Du Vilain au buffet, donde, entre las habilidades de los juglares, figura el recitar la Herberie.

" "Telle est cette seconde partie, dont le déroulement soigné et le réalisme incitent à penser qu'elle aurait pu être la transcription fidèle des paroles d'un authentique herbier, la première n'étant, comme tout boniment à caractère comique, destinée qu'à faire se rassembler la foule et la faire rire" (Aubailly, 1975: 43). Pensamos, por el contrario, que l'Herberie es obra puramente literaria pero que en ella se muestra la habilidad de Rutebeuf _como en sus poesías personales - para acercar la parodia a la realidad. 
acumulan en el haber del mire, algunas tan fantásticas como las piedras traídas: piedras inexistentes, términos inventados, nombres de flores, todo ello transformado en minerales curativos:

\author{
Mout riches pierres en aport \\ Qui font resusciteir le mort: \\ Ce sunt ferrites, \\ Et dyamans et cresperites, \\ Rubiz, jagonces, marguarites, \\ Grenaz, stopaces, \\ Et tellagons et galofaces. \\ De mort ne doutera menaces \\ Cil qui les porte.
}

(vv. 32-40; FB, II: 273-274).

Enumeraciones caóticas (piedras, países, monedas), acumulaciones burlescas, etc., se unen a perogrulladass cómicas (vv. 41-46), relatos maravillosos y absurdos (vv. 50-54), detalles groseros y fantásticos (vv. 62-64), recetas exóticas y soeces (vv. 80-82, 102-106).

La parte en prosa recoge la acumulación de países visitados, repeticiones frecuentes en boca de charlatanes. Ecos de teorías del momento ridiculizadas se mezclan con descripciones de enfermedades fantásticas («et font morir d'une maladie c'on apele mort sobitainne», la muerte repentina convertida en enfermedad causada por los vers). El deseo de novedad del charlatán lleva a hacer un elogio desmedido de una hierba ("artículo en oferta»), en este caso l'armoise, objeto de adorno y artículo "milagroso", de ilimitado poder curativo, verdadero precedente del pantagruelion rabelaisiano ${ }^{9}$. No podía faltar una fuente de comicidad tan explotada en la Edad Media como la burla de algún aspecto del clero, aquí el vivir de "limosnas» hechas a Dios y a los santos: pan y vino para el charlatán, serán su recompensa, heno y avena para su rocín, "car ceil qui auteil sert d'auteil doit vivre».

Hay que demostrar sus conocimientos científicos e históricos para impresionar a los transeúntes y embaucar a las gentes sencillas. El charlatán jura por la pasión con la que Dios maldijo a Corbitas el judio, quien forjó las treinta monedas de plata en la torre de Abilent, a tres leguas de Jerusalén, por las que Cristo fue vendido ( su erudición es inigualable!).

A pesar de su precio reducido, de las facilidades de pago ofrecidas a los

9 Acaso el pantagruelion fuese únicamente un recuerdo de la "hierba milagrosa" medieval; interpretación más trivial, menos sugestiva, sin duda, que la del «humanismo», «saber», etc., pero más acorde con el espiritu cómico de la obra rabelaisiana. 
económicamente débiles, de su eficacia indiscutible, siempre existen gentes reacias: «Qui vodra, si en preingne; qui ne vodra, si les laist!» (FB, II: 280), final malhumorado del charlatán que no ha logrado imponer sus productos al público.

Compuesta de una primera parte en verso y una segunda en prosa, destaca entre las mejores composiciones de Rutebeuf. El metro se adapta perfectamente al desorden de pensamiento, a la acumulación burlesca. El «tercet coué», constituido por la alternancia periódica de octosílabos y tetrasílabos, da a la frase un ritmo de constante cascada; las separaciones métricas interfieren y debilitan las pausas sintácticas.

Arrastradas por el ritmo, subordinadas a la euforia de la palabra, al triunfo de la forma sobre el contenido, las cosas modifican su ser (la marguerite es piedra). Nuevos lugares u objetos surgen ligados a la creación de un nuevo término, cruce de dos existentes o análogo, en la forma, a ellos: ferrites, cresperites, ..., según un procedimiento que, siglos más tarde, hará la celebridad de Rabelais.

Dos perogrulladas interrumpen la enumeración de piedras milagrosas, ambas debidas, no a una idea, sino a una homonimia:

Cil qui les porte.

Foux est se il se desconforte:

N'a garde que lievres l'en porte

S'il se tient bien;

Si n'a garde d'aba de chien

$\mathrm{Ne}$ de reching d'azne anciien

S'il n'est coars;

(vv. 40-46; FB, II: 274).

La obra se aproxima por momentos a las rêveries o a las fatrasies medievales, géneros irracionales, poemas en los que la forma de las palabras gobierna su disposición, prescindiendo de toda ordenación lógica (aunque no todas respondan a esta definición).

La prosa proporcionaba una impresión de mayor realidad. A ella pasa en la segunda parte del dit. Único ejemplo de la prosa rutebeufiana, es un claro precedente de la frase de Rabelais. Emplea una frase amplia, en la que se introducen completivas o relativas. Otros instrumentos de subordinación faltan casi totalmente (salvo nexos temporales). La mera yuxtaposición basta para indicar la causa o la consecuencia. Los párrafos se organizan en grupos de dos: para hacer la presentación de su saber utiliza el método negativo; en un primer momento niega toda interpretación errónea; un segundo período explica su aprendizaje con Madame Trote de Salerno. 
Predomina el estilo nominal. La enumeración, de gran importancia en la novela medieval, procedimiento escolar empleado para destacar un objeto o situación, cobra aquí un valor cómico al superar las proporciones de lo posible. Ninguna palabra queda aislada, sino que todas están sometidas a contraposiciones, precisiones, repeticiones, en el estilo machacón empleado tanto por la predicación como por el charlatanismo. Como en el verso, la palabra engendra la descripción:

...; ainz suis a une dame qui a non ma dame Trote de Salerne, qui fait cuevrechiés de ses oreilles, et li sorciz li pendent a chaainnes d'argent par desus les espaules.

(FB, II, pp. 276-277).

La pintoresca descripción de la dama radica en una asociación de la mujer con el rocín del charlatán, traída por el juego de palabras sobre Trote (deformación de Trotula de Salerno, médico mujer famosa en el siglo xI) y el verbo troter $^{10}$.

¿A qué público estaba destinada la obra? ¿A un grupo de transeúntes o desocupados en una plaza parisiense, o a un público estudiantil? ¿Con qué motivo se escribió esta primera parodia conservada de los herbiers? Se ha puesto en relación con las medidas adoptadas por la facultad de medicina de París, hacia 1271, contra boticarios y herboristas que recetaban y cuidaban enfermos ilegalmente (Faral y Bastin, Rutebeuf, Oeuvres, II: 266). El descontento y desprecio de los medios estudiantiles contra estos intrusos podía favorecer el éxito de la obra y es dificil pensar que Rutebeuf no aprovechase la oportunidad. ¿Se escribiría, en tal caso, para un público estudiantil? Faral y Bastin (ibid.) señalan que ciertas alusiones sólo podia entenderlas un auditorio familiarizado con el cura Juan, con la celebridad de la facultad de medicina de Salerno, con la mujer médico, Trótula de Salerno o Trótola de Roggeri, con la teoría médica de lo caliente y lo húmedo, con la historia de los treinta denarios de Judas, etc. Es posible que, en un principio, fuese representada ante un público de escolares, pero la obra, sin duda, se difundió en otros ambientes, ya que entró a formar parte del re-

${ }^{10}$ Faral y Bastin, Rutebeur, Oeuvres, II, p. 276, n. 2, han rebatido esta interpretación de Picot (1970: 122), considerando la imagen de un burlesco gratuito. Juzgamos más probable la interpretación de Picot. Estos juegos de palabras son frecuentes en Rutebeuf; la deformación del nombre parece apuntar en este sentido y asi debieron de sentirlo los contemporáneos, ya que otros manuscritos (ms. D) nos presenta otra forma equivoca, crote. 
pertorio de los juglares, como documenta la alusión del Vilain au buffet ${ }^{\prime \prime}$ y contó con diversas refundiciones simplificadas, en las que se suprimieron estas alusiones y se sobrecargaron las bromas y burlas groseras.

Seigneur qui ci este venu,

Asseeiz vos, ne faites noise,

Si escoutez, s'il ne vos poize.

(vv. 1 y 8-9; FB, II: 272).

Esta introducción ha hecho pensar en una verdadera escenificación, representación teatral, ante un público sentado, reunido en una sala, y no un público de transeúntes (Picot, 1970: 121-122). La existencia de ejemplos análogos en obras indiscutiblemente destinadas a una lectura oral ${ }^{12}$, nos obliga a manejar este dato con precaución. Podría tener sencillamente un valor irónico; una sonrisa subrayaría lo insólito de la orden para un público de pie y apiñado alrededor del pseudo-charlatán. Podría suponerse una representación en una sala, ante un público de estudiantes, pero es dificil

L'uns fait l'ivre, l'autre le sot;

Li uns chante, li autres note,

Et li autres dit de la Riote

Et li. autres la Jenglerie...

Aucuns i a qui fabliaus conte,

Ou il ot mainte gaberie,

Et li autre dit l'Erberie.

La ou il ot mainte risee.

(vv. 142-149; Faral, 1910: 58-59; Faral y Bastin, Rutebeuf, Oeuvres, II: 266-267).

Al reproducir el párrafo, Faral escribe con mayúsculas Riote, Jenglerie, considerándolas titulos de obras, como l'Erberie; por el contrario, en la edición de Montaiglon y Raynaud (1973 III: 204), riote y jenglerie son tratados como nombres comunes y transcritos sin mayúsculas ni bastardilla. Consideramos más acertada la interpretación de Faral.

Escoutez donc, ne fetes noise,

Si orrez ja, s'il ne vous poise,

(Rutebeuf, Vie de Ste. Elysabel, vv. 197198, FB, II: 107). 
pensar en una auténtica escenificación en una época en la que, salvo en Arras, se desconocía la representación de obras cómicas.

Tal vez la obra encerrase una protesta universitaria contra los intrusos que se entrometían en las tareas reservadas a los estudiantes de medicina. En tal caso sería presentada ante una reunión de estudiantes. Pero pronto, en la forma en la que nos ha llegado o en diferentes adaptaciones, pasó a recitarse ante un público más heterogéneo. El género agradó; aportaba una forma nueva a la apetencia medieval de obras cómicas, burlescas y paródicas. Nos han llegado dos obras análogas del mismo siglo: l'Herberie en prosa, antes considerada, y la Goute en l'aine ${ }^{13}$. El octosílabo pareado sustituye, en esta última, al tercet coué; se simplifican las alusiones pedantes pero permanecen las enumeraciones caóticas, la profusión de recetas médicas, el orgullo del charlatán:

Je suis bons mire de Salerne;

Fols est qui blasme ne qui ferne

Le grant sens que Diex m'a doné

Et que j'ai piecà conquesté

A Paris \& a Montpellier, Dont je ving d'escole l'autr'ier.

(vv. 7-12).

No existe diferencia en cuanto al personaje; el herbier de Rutebeuf se define también como «je sui uns mires» (v. 10).

Del monólogo del herbier, parodia universitaria de los pseudo-médicos, surgirá una nueva forma literaria; de él se pasará al «Hombre que todo lo sabe hacer» de Raymond de Aviñón, también del siglo XIII, único ejemplo

La declaración de la sirvienta se inicia con una fórmula análoga, que no tiene más valor que proporcionar dos versos tópicos. La facilidad de versificación produce un contrasentido:

«Or escoutez, traiez vous prés,

S'orrez", dist ele, "de celi"

(Ibidem, vv. 274-275, FB, II: 109).

"' Edición: Jubinal, Rutebeuf, Oeuvres Complètes, 1839, I: 475-477; 1875, III: 192-194. (Se cita por la segunda edición de 1875). 
provenzal y, finalmente, al Watelet de tous metiers (hacia 1500) y sus epigonos. La voz del herborista volverá a oírse, poco antes de que la Pléyade y las reuniones "humanistas" se apresten a acabar con la pervivencia de los géneros medievales, en el Monologue nouveau et fort récréatif de la fille batelière (Rouen, hacia 1540), «Fille d'un bateleur» (v. 5), es decir, criada de un farsante y titiritero, conoció la ciencia de su maestro, viajó por todas las ciudades de Francia y todos los países del mundo, recogiendo drogas aptas para curar todas las enfermedades. Al público ofrece su mercancia en versos que recuerdan a algunos de Rutebeuf:

Se la personne estoyt gouteuze

Ou desus la partye honteuze

Le chancre l'avoit assailye,

Soudainement seroyt guerye

Devant que partir de mes mains.

Or ça, levés trestous les mains,

Petis et grans, sans secrupules.

Qui n'era grandz blanz ou sizains,

Je prendray bréves et cedules.

(vv. 108-116; Picot, 1970: 144).

Pero el herbier, el mire, se ha convertido en una chambrière de bateleur, de titiritero, de farsante, de comediante. El dit se ha hecho monólogo dramático; ha tomado plenamente conciencia de sus posibilidades teatrales. Lo que en un principio era una obra de circunstancias y una parodia resentida, probablemente apoyada por el público de las facultades, contra sus competidores, se ha convertido en pretexto para mostrar la habilidad de un comediante. Inconscientemente Rutebeuf había creado uno de los géneros más aplaudidos en los siglos XV y XVI. 


\section{REFERENCIAS BIBLIOGRÁFICAS}

Aubailly, J.-Cl. (1975), Le Théâtre médiéval profane et comique, Paris, Larousse.

- (1976), Le Monologue, le dialogue et la sottie. Essai sur quelques genres dramatiques de la fin du Moyen Âge et du début du XVI siècle, Paris, Champion.

Braet, H.; Nowe, J. y Tournoy, G. (eds.), (1985), The Theatre in the Middle Âge, Leuven Univ. Press.

Chambers, E. K. (1903), The Mediaeval Stage, 2 vol., Oxford Univ. Press.

Clédat, L. (1896), Le Théâtre en France au Moyen Âge, Paris, Lecène, Oudin et Cie.

CoHen, G. [1941], Le Théâtre comique au Moyen Âge, Paris, C.D.U., s.f.

- (1948), Le Théâtre en France au Moyen Âge. I. Le Théâtre religieux. II. Le Théâtre profane, 2." ed. en 1 vol., Paris, P.U.F.

- (1956), Études d'histoire du théâtre en France au Moyen Âge et à la Renaissance, 7." ed., Paris, Gallimard.

Des Granges, Ch. M. (1897), De Scenico Soliloquio (gallice: Monologue dramatique) in nostro medii aevi Theatro, Paris, E. Bouillon.

FARAL, Ed. (1910), Mimes français du XIII siècle. Contribution à l'histoire du théâtre comique du Moyen Âge, Paris, Champion. (Reimpr. Ginebra, Slatkine, 1973).

- (1924), “Le Fabliau latin au Moyen Âge», Romania 50, pp. 321-385.

- (1942), La Vie quotidienne au temps de Saint Louis, nueva ed., Paris, Hachette.

Frank, Gr. (1954), The Medieval French Drama, Oxford, Clarendon Press. 
FrappIER, J. (1960), Le Thêatre profane en France au Moyen Âge, XIII et XIV siècles, Paris, C.D.U.

Garapon, R. (1957), La Fantaisie verbale et le comique dans le théâtre français du Moyen Âge à la fin du XVII' siècle, Paris, A. Colin.

JACOBSEN, J.-P. (1909), «La Comédie en France au Moyen Âge», Revue de philologie française et de littérature, 23, pp. 1-22, 81-106, 161-196.

KNIGHT, A. E. (1983), Aspects of Genre in the Late Medieval French Drama, Manchester Univ. Press.

Konigson, E. (1975), L'Espace théâtral médiéval, Paris, Éds. du C.N.R.S.

Koopmans, J. (ed.) (1984), Quatre sermons joyeux, Ginebra, Droz.

- (ed.) (1988), Recueil de sermons joyeux, Ginebra, Droz.

KoOPMANS, J. y VERHUYCK, P. (1986), «Quelques sources et parallèles des sermons joyeux français des $\mathrm{XV}^{e}$ et $\mathrm{XVI}^{e}$ siècles, Neophilologus 70, pp. 168-184.

- (1987), Sermon joyeux et truanderie (Villon - Nemo - Ulespiègle), Amsterdam, Rodopi.

Lehmann, P. (1963), Die Parodie im Mittelalter, 2." ed., Stuttgart, A. Hiersemann.

Lemaire, J. (1983), "A propos du monologue dramatique médiéval», en Debusscher, G. y Van Crugten, A. (eds.), Théâtre de toujours. D'Aristote à Kalisky. Hommages à Paul Delsemme, Bruselas, Ed. de l'Univ. de Bruxelles.

LewickA, H. (1980), Bibliographie du théâtre profane français des $X V^{e}$ et $X V I^{e}$ siecles, 2." ed., Paris, Eds. du CNRS.

LEWICKA, H. y JAROSZEWSKA (1987), Bibliographie du théâtre profane français des $X V^{e}$ et $X V I^{e}$ siècles. Supplément, Paris, Éd. du CNRS.

Lintilhac, E. (1973), Histoire générale du théâtre en France. I. Le Théâtre sérieux du Moyen Âge. II. La Comédie. Moyen Âge et Renaissance, 2 vols., Ginebra, Slatkine (reimpr. de la ed. de Paris, Flammarion, s.f. [1904-1905]).

Montaiglon, A. De y Raynaud, G. (1973), Recueil général et complet des Fabliaux des $X I I I^{\circ}$ et $X I V^{\prime}$ siècles, 6 vol., Ginebra, Slatkine (reimpr. de la ed. de 18721890). 
Mortensen, J. (1903), Le Théâtre français au Moyen Âge, trad. fr., Paris, Picard.

Muller, G. R. (ed.) (1981), Le Théâtre du Moyen Âge. Actes du deuxième Colloque de la Socité Int. pour l'Etude tu Théâtre Médiéval. Alençon, 11-14 juillet 1977, Montréal, Les Editions Univers Inc.

Petit de Julleville, L. (1885), Les Comédiens en France au Moyen Âge, Paris, L. Cerf.

- (1886a), La Comédie et les moeurs en France au Moyen Âge, Paris, L. Cerf.

- (1886b), Répertoire du théâtre comique au moyen âge, Paris, L. Cerf.

Picot, E. (1970), Le Monologue dramatique dans l'ancien théâtre français, Ginebra, Slatkine (reimpr. de la ed. de 1886-1888).

Picot, E. y Nyrop, Chr. (1880), Nouveau recueil de farces françaises des $X V^{*}$ et $X V I^{\circ}$ siècles, Paris, Morgand et Fatout.

Rolland, J. (1945), Essai paléographique et bibliographique sur le théâtre profane en France avant le $X V^{e}$ siècle, Paris, Bibl. d'Histoire littéraire. (Nueva ed. en un vol. de: 1. Les Origines latines du Théâtre comique en France, 1927; II. Le Théâtre comique avant le $X V^{e}$ siècle, 1930).

Rutebeuf (1874-1875), Oeuvres complètes, ed. de A. Jubinal, 2.. ed., 3 vol., Paris, A. Daffis (1." ed., 2 vol., 1839).

- (1969), Oeuvres complètes, ed. de Ed. Faral y J. Bastin, 2 vol., nueva reimpr., Paris, Picard.

- (1989-1990), Oeuvres complètes, ed. y trad. de M. Zink, 2 vol., Paris, Bordas (Classiques Garnier). 